|| ISSN(online): 2589-8698 || ISSN(print): 2589-868X || International Journal of Medical and Biomedical Studies

Available Online at www.ijmbs.info

PubMed (National Library of Medicine ID: 101738825)

Index Copernicus Value 2018: 75.71

Original Research Article

Volume 3, Issue 6; June: 2019; Page No. 259-262

\title{
CAESAREAN SECTION AND BLADDER INJURY
}

\section{Dr. Manish Bhatt ${ }^{1}$, Dr. Ela Bhatt ${ }^{2}$}

Assistant Professor Dept. of General Surgery Ananta Institute of Medical Science and Research Centre Rajsamand

Assistant Professor, Dept. of OBGY Ananta Institute of Medical Science and Research Centre Rajsamand.

Article Info: Received 30 May 2019; Accepted 28 June. 2019

DOI: https://doi.org/10.32553/ijmbs.v3i6.354

Address for Correspondence: Dr. Ela Bhatt, Assistant Professor, Dept. of OBGY Ananta Institute of Medical Science and Research Centre Rajsamand.

Conflict of interest: No conflict of interest.

\begin{abstract}
INTRODUCTION: Cesarean section is a live saving procedure but when performed without appropriate indications can add risk to both mother and baby. As per WHO report, at population level, Cesarean section rates higher than $10 \%$ are not associated with reductions in maternal and new-born mortality rates. In India as per District level household survey 3 (DLHS) Cesarean section rate is $28.1 \%$ in private sector and $12 \%$ in public sector health care facilities. The close embryonic development and anatomical proximity of the urinary bladder and genital organs, are responsible for the urinary tract to injury during surgical procedures in the female pelvis. During LSCS bladder injury is demonstrated by the presence of gas filling up the Foley bag or visibly bloody urine in the Foley bag. Veress needle injuries and other small injuries to the bladder can be successfully managed conservatively by catheter drainage for seven to 14 days followed by cystography while large bladder injuries, such as from 5 or $10 \mathrm{~mm}$ trocar or surgical dissection usually require suturing the injuries closed. Risk factors for bladder injury during LSCS include previous operations, expodure to radiation, malignancy, chronic infection, and inflammation.
\end{abstract}

MATERIAL AND METHODS: In suspected cases of bladder injuries cystogram X-ray of the bladder after injection of contrast medium is performed. For extraperitoneal injuries (grade 2) without complicating factors, treatment is a insertion of Foley catheter for 7 - 14 days. grade 3 to grade 5 injuries generally require operative repair. Closed suction drains should be left in place after repairs. Suprapubic tube placement is not necessary in most cases. For injuries to the ventral bladder, dome, or posterior bladder, the mucosa is closed in a running fashion using 3-0 vicryl followed by a seromuscular running suture of 2-0 vicryl. The bladder is irrigated to ensure a watertight closure. A third layer in a Lembert fashion can be used in cases at high risk for fistula formation or when a leak is identified. In the laparoscopic setting, a one-layer closure is performed using 2-0 vicryl to close all layers of the bladder. An additional layer can then be added using a 2- 0 vicryl in a Lembert fashion for more extensive injuries.

RESULTS: There were 986 LSCS done in the department of Obstetrics and gynaecology in the given study period. Of which 14 were diagnosed with the bladder injuries during. Among all patients who suffered from bladder injury, 3 cases were primigravida and 11 were multigravida type. Out of 14injuries, 10 injuries were repaired in 2 layers by vicryl 2.0 without insertion of SPC (suprapubic cystectomy) whereas 4 injuries were repaired by primary repair with vicryl 2.0 with insertion of SPC. In post-operative period patients were monitored for vitals, urine output and stitch sites of wounds. No complications were found in 13 patients post operatively and Foleys catheter and SPC catheter were removed after 12 days of operation in those patients.

CONCLUSION: $1.4 \%$ of the bladder injuries were observed. Early detection and prompt management of bladder injury can decrease the morbidity and mortality in LSCS cases

\section{Introduction}

Cesarean section is a live saving procedure but when performed without appropriate indications can add risk to both mother and baby. As per WHO report, at population level, Cesarean section rates higher than $10 \%$ are not associated with reductions in maternal and new-born mortality rates'. In India as per District level household survey 3 (DLHS) Cesarean section rate is $28.1 \%$ in private sector and $12 \%$ in public sector health care facilitiesii. This survey shows that Cesarean deliveries in institutional births have increased randomly in India, especially in private sector health care sectors. Also it has been shown that there are various reasons for increase in 
Cesarean section like patient's preferences, social norms, fear of vaginal delivery ${ }^{\mathrm{iii}}$, iv.

The close embryonic development and anatomical proximity of the urinary bladderand genital organs, are responsible for the urinary tract to injury during surgical procedures in the female pelvis ${ }^{\mathrm{v}}$.

In gynecologic surgery, bladder injury commonly occurs during abdominal hysterectomy. Bladder can be managed by a two- or three-layer closure with absorbable suture and Foley catheter bladder drainage and bladder filling with blue-colour saline again makes bladder injury diagnosis easier ${ }^{\mathrm{vi}}$.

During LSCS bladder injury is demonstrated by the presence of gas filling up the Foley bag or visibly bloody urine in the Foley bag. Veress needle injuries and other small injuries to the bladder can be successfully managed conservatively by catheter drainage for seven to 14 days followed by cystography while large bladder injuries, such as from 5 or $10 \mathrm{~mm}$ trocar or surgical dissection usually require suturing the injuries closed ${ }^{\text {vii }}$.

Risk factors for bladder injury during LSCS include previous operations, expodure to radiation, malignancy, chronic infection, and inflammation. Sometimes unrecognized bladder injury usually present clinically in the early postoperative period. Signs and symptoms of unrecognized bladder injury can be drainage from a surgical incision, increased output from surgical drains, vaginal leakage, apparent oliguria, and urinary ascites ${ }^{\text {viii. }}$

\section{MATERIAL AND METHODS}

Present study was carried out in the dept. of General Surgery in collaboration with Dept. of OBGY at Ananta Institute of Medical Science and Research Centre Rajsamand. This study was done in the department of Gynaecology in collaboration with department of surgery. This was a Prospective interventional study. Written informed consent from all the participants was taken.

There were 986 LSCS done in the department of Obstetrics and gynaecology in the given study period. Of which 14 were diagnosed with the bladder injuries during.

Diagnosis of the injuries to bladder was as follows

Staging of the bladder injuries ${ }^{\mathrm{ix}}$.

Grade 1: contusion, intramural hematoma or partial thickness laceration
Grade 2: extraperitoneal bladder wall laceration $2 \mathrm{~cm}$ or intraperitoneal $2 \mathrm{~cm}$

Grade 3: extraperitoneal $>2 \mathrm{~cm}$ or intraperitoneal 2 $\mathrm{cm}$

Grade 4: intraperitoneal bladder wall laceration $>2$ $\mathrm{cm}$

Grade 5: intra- or extraperitoneal bladder wall laceration involving the trigone or bladder neck.

In suspected cases of bladder injuries cystogram Xray of the bladder after injection of contrast medium is performed

For extraperitoneal injuries (grade 2) without complicating factors, treatment is a insertion of Foley catheter for 7 - 14 days. grade 3 to grade 5 injuries generally require operative repair. Closed suction drains should be left in place after repairs. Suprapubic tube placement is not necessary in most cases. For injuries to the ventral bladder, dome, or posterior bladder, the mucosa is closed in a running fashion using 3-0 vicryl followed by a seromuscular running suture of 2-0 vicryl. The bladder is irrigated to ensure a watertight closure. A third layer in a Lembert fashion can be used in cases at high risk for fistula formation or when a leak is identified. In the laparoscopic setting, a one-layer closure is performed using 2-0 vicryl to close all layers of the bladder. An additional layer can then be added using a 2- 0 vicryl in a Lembert fashion for more extensive injuries

Present data was inserted in the Microsoft Excel worksheet and was analysed for percentage, grading of injury, repair of bladder and complications .

\section{RESULTS}

In our study 986 patients were operated for LSCS of which 14 had bladder injuries.

Table 1: Showing injury of patients during cesarean

\begin{tabular}{|l|l|l|l|}
\hline Injury & $\begin{array}{l}\text { Bladder } \\
\text { Injury }\end{array}$ & $\begin{array}{l}\text { No bladder } \\
\text { injury }\end{array}$ & Total \\
\hline Cesarean section & $14(1.4 \%)$ & $972(98.6 \%)$ & 986 \\
\hline
\end{tabular}

Among all patients who underwent cesarean section $1.4 \%$ suffered from bladder injury.

Table 2: Showing Gravida Type

\begin{tabular}{|l|l|}
\hline Gravida type & Count \\
\hline Primi & 3 \\
\hline Multigravida & 11 \\
\hline Total & 14 \\
\hline
\end{tabular}


Among all patients who suffered from bladder injury, 3 cases were primigravida and 11 were multigravida type.

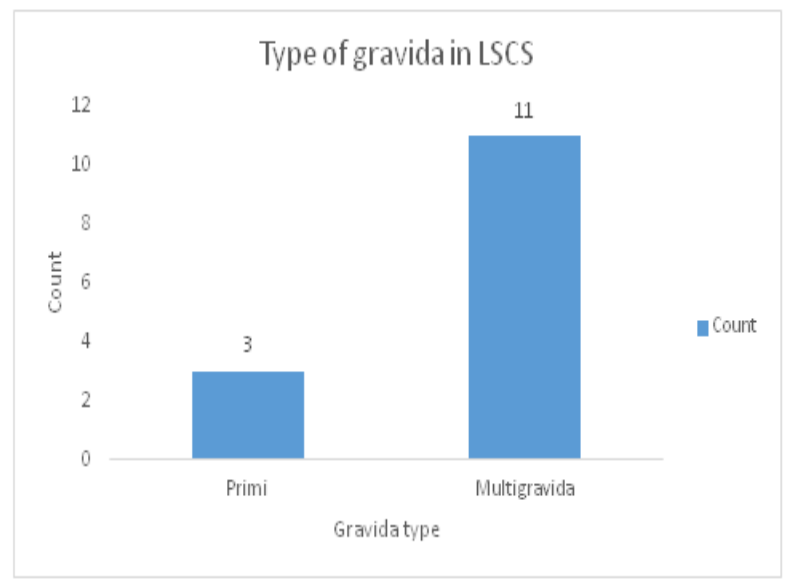

Figure 1: Type of gravida in LSCS

Table 3: Shows repairs

\begin{tabular}{|l|l|}
\hline Repairs & Count \\
\hline Vicryl 2.0 without SPC & 10 \\
\hline Vicryl 2.0 with SPC & 4 \\
\hline Total & 14 \\
\hline
\end{tabular}

Out of 14injuries, 10 injuries were repaired in 2 layers by vicryl 2.0 without insertion of SPC (suprapubic cystectomy) whereas 4 injuries were repaired by primary repair with vicryl 2.0 with insertion of SPC. In post-operative period patients were monitored for vitals, urine output and stitch sites of wounds. No complication were found in 13 patients post operatively and Foleys catheter and SPC catheter were removed after 12 days of operation in those patients. They were discharged after 15 days of operation. 1 complication of surgical site was treated with antibiotics and discharged after 26 days.

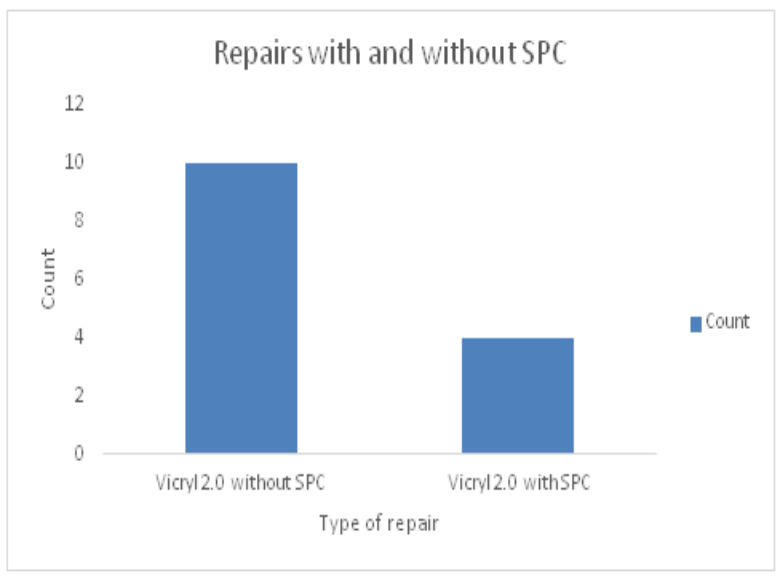

Figure 2: Type of repair in injuries with and without SPC

\section{DISCUSSION:}

Cesarean delivery (CD) is one of the most common obstetric surgeries. Adhesions are because of abnormal wound healing. ${ }^{x}$ A fibrin clot is generally formed by the aggregation of blood cells, platelets and clotting of the blood. If fibrinolysis is suppressed i.e., by tissue ischemia and hypoxia, then fibrin deposits may persist and develop into adhesions. Other factors include residual blood, postoperative infection, inflammation and foreign bodies (e.g., sutures $^{x i}$. The knowledge and understanding of anatomy is the most important tool for a surgeon. ${ }^{\mathrm{xi}}$ During pelvic surgery, the urinary tract is predisposed to injury due to close anatomic association of genital and urinary organ ${ }^{5}$.

In present study 986 patients were operated for LSCS of which $14(1.4 \%)$ had bladder injuries. In all 14 injuries, 11 cases were of multigravida and 3 were primigravida cases.

Out of 14 bladder injuries, 11 were detected intraoperatively during urinary leakage and 3 were detected post operatively. Among 14 injuries of bladder, 10 injuries were repaired without insertion of SPC in 2 layers by vicryl 2.0 whereas 4 injuries were repaired with SPC by primary repair with vicryl 2.0. Less morbidity and better quality of life is provided by intraoperative corrections. ${ }^{\text {xii }}$

\section{CONCLUSION}

In our study $1.4 \%$ of the bladder injuries were observed. Early detection and prompt management of bladder injury can decrease the morbidity and mortality in LSCS cases

\section{REFERENCES}

1. Souza J, Gulmezoglu A, Lumbiganon P, et al. Cesarean section without medical indications is associated with an increased risk of adverse short-term maternal outcomes: the 2004-2008 WHO global survey on maternal and perinatal health. BMC Med. 2010;8:71. doi: 10.1186/17417015-8-71.

2. District level household \& facility survey (DLHS3) [Internet]. Mumbai: International Institute for Population Sciences. Available from: http:// rchiips.org/PRCH-3.html

3. Yoshioka-Maeda K, Ota E, Ganchimeg T, Kuroda $M$, Mori R. Cesarean section by maternal age group among singleton deliveries and 
primiparous Japanese women: a secondary analysis of the WHO global survey on maternal and perinatal health. BMC Pregnancy Childbirth. 2016;16(1):39. doi: 10.1186/s12884016-0830-2.

4. Behague DP, Victora CG, Barros FC. Consumer demand for cesarean sections in Brazil: informed decision making, patient choice, or social inequality? A population based birth cohort study linking ethnographic and epidemiological methods. BMJ. 2002;324(7343):942. doi: 10.1136/bmj.324.7343.942.

5. Raut V, Shrivastava A, Nandanwar S, Bhattacharya M. Urological injuries during obsteteic and gynecological surgical procedures. J Postgrad Med. 1991;37:21-3.

6. Ricardo Azziz, Geoffrey W. Cundiff, Robert E Bristow. Linde's Atlas of Gynecologic Surgery. Lippincott Williams and Wilkins. 64 ed.2014.

7. Mann WJ, Arato M, Patsner B, Stone ML. Ureteral injuries in an obstetrics and gynecology training program: etiology and management. Obstet Gynecol. 1988;72:82-5.

8. Vaidya $B$, Chaudhari M, Parmar D, Chaudhari V, Daginawala T, Shah R. Bladder injuries during obstetrical and gynecological surgeries. IntSurg J 2017;4:2177-80.

9. Van Goor H. Consequences and complications of peritoneal adhesions. Colorectal Dis. 2007;9(s2):25- 34.

10. Chegini $N$, Zhao $Y$, Kotseos $K$ et al. Differential expression of matrix metalloproteinase and tissue inhibitor of MMP in serosal tissue of intraperitoneal organs and adhesions. BJOG 109(9), 1041-1049 (2002).

11. Roset $E$, Boulvain $M$, Irion $O$. Nonclosure of the peritoneum during caesarean section: long-term follow-up of a randomised controlled trial. Eur. J. Obstet. Gynecol. Reprod. Biol. 108(1), 40-44 (2003).

12. Francis SL, Magrina JF, Novicki DE, Cornella JL. Intraoperative injuries of the urinary tract. CME J GynecolOncol. 2002;7:65-77.

13. Turk SK, Muneer L, Memon AS. Treatment of Gyneco-logical and obstetric ureteric injuries. J surg Pakistan Int. 1999;4:31-4. 